\title{
Correction to: Nitrous oxide emission factors in conventionally and naturally simulated cattle urine patches
}

\author{
M. O’Neill • S. Saggar $\cdot$ K. G. Richards $\cdot$ J. Luo $\cdot$ B. P. Singh $\cdot$ P. Mehra \\ P. J. Forrestal
}

Published online: 7 October 2021

(C) The Author(s), under exclusive licence to Springer Nature B.V. 2021

\section{Correction to: Nutr Cycl Agroecosyst https://doi.org/10.1007/s10705-021-10162-5}

In the original publication of the article Fig. 1 contains the meteorological data of all three experimental sites (NZ1, NZ2 and IRE) rather than the meteorological data for only the NZ1 site as labelled. This has been corrected with this Correction.

The original article can be found online at https:// doi.org/10.1007/s10705-021-10162-5.

M. O’Neill ( $\bowtie) \cdot$ K. G. Richards · P. J. Forrestal Teagasc, Environment, Soils and Land Use Department, Johnstown Castle Research Centre, Co. Wexford, Ireland e-mail: macdara.oneill@teagasc.ie

S. Saggar

Manaaki Whenua -Landcare Research, Palmerston North, New Zealand

J. Luo

AgResearch Ruakura Research Centre, Private Bag 3123, Hamilton, New Zealand

B. P. Singh $\cdot$ P. Mehra

NSW Department of Primary Industries, Elizabeth Macarthur Agricultural Institute, Menangle, Australia 

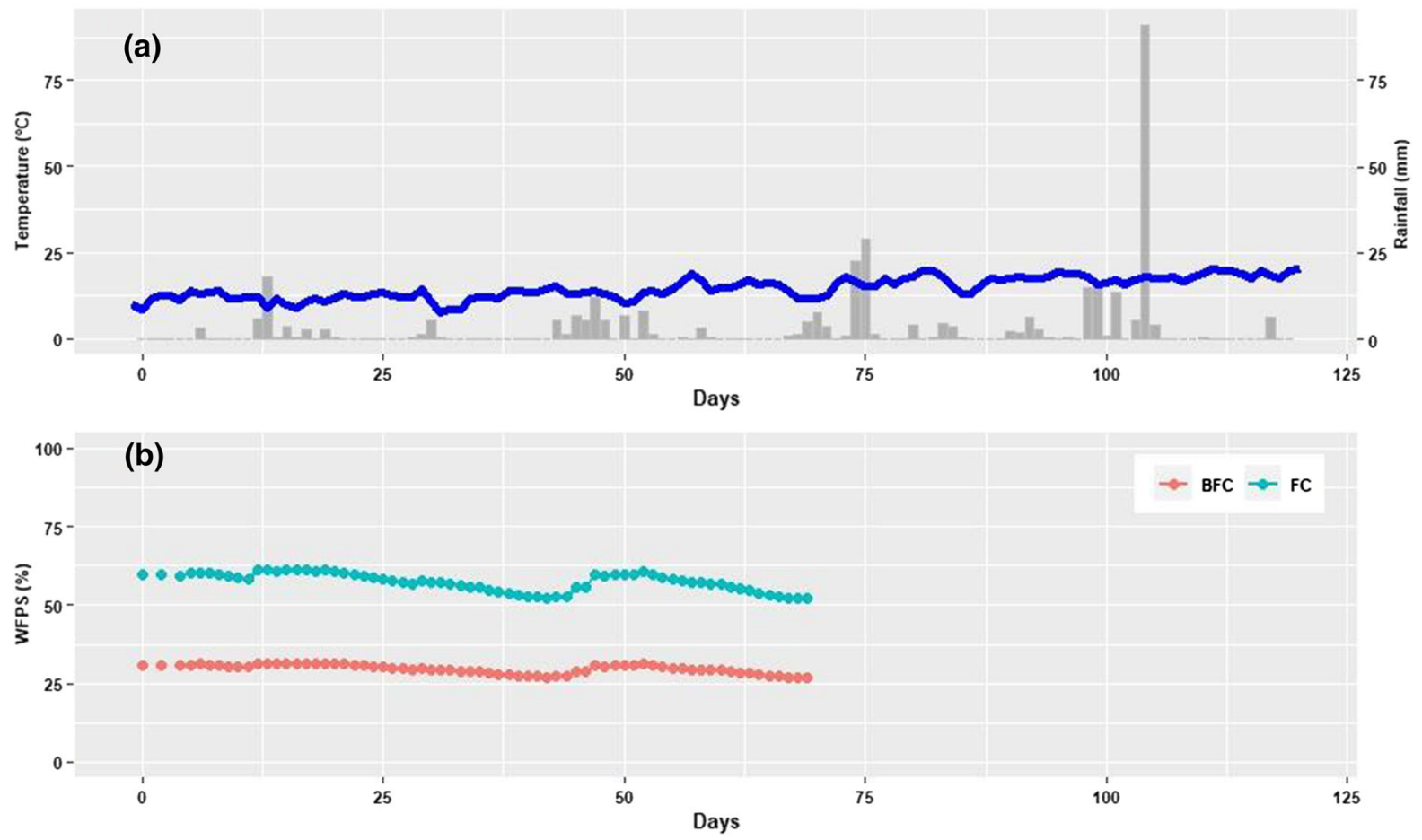

Fig. 1 Daily air temperature $\left({ }^{\circ} \mathrm{C}\right)$, rainfall $(\mathrm{mm})$ and WFPS $(\%)$

obtained from the mean soil volumetric water content measured data in NZ1. Air temperature and rainfall was obtained from the at $50 \mathrm{~mm}$ and $100 \mathrm{~mm}$ depths using time-domain reflectometers

Publisher's Note Springer Nature remains neutral with regard to jurisdictional claims in published maps and institutional affiliations. 